\title{
Pelatihan Cara Pembuatan Makanan Ringan Rendah Gula bagi Penderita Diabetes Mellitus (DM)
}

\section{Training Make Low Sugar Light Food for Diabetes Mellitus (DM) Patients}

\author{
${ }^{1}$ Fatma Zulaikha, ${ }^{2}$ Enok Sureskiarti , ${ }^{2}$ Nunung Herlina \\ ${ }^{1}$ Program Studi Ners Fakultas Ilmu Kesehatan dan Farmasi Universitas Muhammadiyah \\ Kalimantan Timur \\ 2 Program Studi S1 Keperawatan Fakultas Ilmu Kesehatan dan Farmasi Universitas \\ Muhammadiyah Kalimantan Timur
}

Korespondensi: E. Sureskiarti es202@umkt.ac.id

Naskah Diterima: 7 Januari 2019. Disetujui: 26 Januari 2020. Disetujui Publikasi: 27 Januari 2020

\begin{abstract}
Diabetes Mellitus (DM) is metabolic disorder, one of the symptoms in this condition is polyphagia (easily hungry). The condition of polyphagia in DM patients can be overcome by providing nutrients that contain low sugar levels so as not to trigger an increase in blood glucose levels in DM patients. Oatmeal crackers biscuit are biscuits made from oats. Quaker oats are nutrients derived from wheat, these nutrients can help treat the condition of type 2 diabetes and can be consumed at all ages. In addition, oats are easy to find. Community service is in the form of training in making biscuit crackers oatmeal chocochips which are processed biscuits with a composition of oats, sweeteners and chocochips. Biscuit is a processed food that is simple, easily made, not found on the market and is the right choice for people with diabetes mellitus. The purpose of this training is to increase cadre knowledge about DM and improve cadre skills in making biscuit crackers oatmeal chocochips. The training was carried out by involving 10 Nasyiatul aisyiyah cadres in Samarinda Ilir, conducted for 8 weeks. The training method was initiated by educating cadres on DM in the first week, followed by training in making biscuits in the second week. 3rd week to 8 th week is assistance for cadres in making biscuits while evaluating cadres 'ability in making biscuits and evaluating participants' knowledge about DM. From the evaluation results, the majority of respondents had good knowledge about DM and were able to make biscuits appropriately.
\end{abstract}

Keywords: Training, biscuit, crackers, DM

\begin{abstract}
Abstrak. Diabetes Mellitus (DM) merupakan gangguan metabolik, salah satu gejala pada kondisi tersebut yaitu polifagia (mudah lapar). Kondisi polifagia pada penderita DM dapat diatasi dengan pemberian nutrisi yang mengandung kadar gula rendah sehingga tidak memicu kenaikan kadar glukosa darah pada penderita DM. Biscuit crackers oatmeal merupakan biscuit yang berbahan dasar oat. Quaker oats merupakan nutrisi yang berasal dari gandum, nutrisi ini dapat membantu mengobati kondisi diabetes tipe 2 serta dapat dikonsumsi segala usia. Selain itu, oat mudah ditemukan. Pengabdian masyarakat ini berupa pelatihan pembuatan biscuit crackers oatmeal chocochips yang merupakan olahan biscuit dengan komposisi oat, pemanis dan chocochips. Biscuit ini merupakan makanan olahan yang sederhana, mudah dibuat, tidak ditemukan di pasaran dan merupakan pilihan tepat bagi penderita diabetes mellitus. Tujuan pelatihan ini yaitu meningkatkan pengetahuan kader mengenai DM dan meningkatkan ketrampilan kader dalam membuat biscuit crackers oatmeal chocochips. Pelatihan dilakukan dengan melibatkan 10 kader Nasyiatul aisyiyah Samarinda Ilir, dilakukan selama 8 minggu. Metode pelatihan diawali dengan mengedukasi kader mengenai DM pada minggu pertama, dilanjutkan dengan pelatihan pembuatan biscuit pada minggu kedua. Minggu ke-3 hingga minggu ke-8 merupakan pendampingan bagi kader dalam pembuatan biscuit sekaligus
\end{abstract}


mengevaluasi kemampuan kader dalam pembuatan biscuit serta mengevaluasi pengetahuan peserta mengenai DM. Dari hasil evaluasi didapatkan mayoritas responden memiliki pengetahuan yang baik mengenai DM dan mampu membuat biscuit secara tepat.

Kata Kunci: Pelatihan, biskuit, crackers, DM

\section{Pendahuluan}

Prevalensi Diabetes Mellitus (DM) di Indonesia menurut Konsensus 2015 Perkeni mencapai 10,9\% pada tahun 2018. Sementara pada tahun 2013 mencapai 6,9 \%, hal ini menandakan adanya peningkatan prevalensi DM di Indonesia. Provinsi Kalimantan Timur merupakan salah satu provinsi di Indonesia yang memiliki prevalensi DM di Indonesia yaitu mencapai $2 \%$ pada tahun 2013 dan mengalami peningkatan pada tahun 2018 yaitu mencapai 3\%(Riskesdas, 2018).

DM (Diabetes Mellitus) menurut Kemenkes (2014) merupakan penyakit gangguan metabolik yang disebabkan karena kerusakan pankreas sehingga menyebabkan produksi insulin tidak mencukupi bagi tubuh. Pada penderita DM akan merasa sering lapar hal ini dikarenakan adanya gangguan pada hormon insulin. Fungsi hormon ini salah satunya adalah menurunkan kadar gula dalam darah dengan cara merangsang sel untuk menyerap gula. Ketika hormon ini terganggu, maka kadar gula dalam darah meningkat tanpa adanya penyerapan gula oleh sel, sehingga tidak terjadi glikolisis yang nantinya menjadi ATP untuk energi aktifitas, ini penjelasan untuk lemah/lemas. DM merupakan salah satu penyakit metabolik yang mengganggu kinerja sistem tubuh sehingga saat DM terjadi dapat menimbulkan dampak kerusakan atau gangguan pada sistem lain. Komplikasi yang dapat muncul pada DM yaitu gangguan jantung dan stroke, gangguan ginjal, gangguan saraf (neuropati diabetikum), pada penderita DM resiko kematian 2 kali lebih besar dibanding non penderita diabetes, dalam hal ini disebabkan karena DM berdampak pada kerusakan sistem organ tubuh(Pusdatin Kemenkes, 2014). DM tipe 2 merupakan jenis diabetes yang sering ditemukan pada kalangan usia 40 tahun, namun prevalensinya tiap tahun mengalami peningkatan, bahkan ditemukan juga penderita DM berusia remaja dan dewasa muda. Peningkatan prevalensi DM dipicu oleh gaya hidup tidak sehat, kurang olahraga, makan manis lebih sering dan meningkatnya jumlah penderita obesitas (Nair \& Peate, 2015).

Penatalaksanaan pada pengendalian dan pencegahan komplikasi DM menurut Kemenkes (2014) diantaranya perawatan kaki diabetes mellitus, pengelolaan diet sehat diabetes mellitus, merutinkan senam penyakit tidak menular, monitoring dan pengendalian faktor resiko. Pengendalian faktor risiko dapat dilakukan di layanan kesehatan primer. Tujuan dari penatalaksanaan DM yaitu untuk mengurangi gejala, mengatur kadar glukosa tetap stabil dan mencegah munculnya komplikasi. Tindakan keperawatan yang dapat dilakukan pada penderita DM meliputi mengajarkan mengenai diet tepat diabetes mellitus, menganjurkan kegiatan fisik harian dan rutin, menganjurkan untuk mengontrol berat badan mencapai normal, menganjurkan untuk berhenti merokok, menganjurkan pasien dan keluarga untuk memantau kadar glukosa darah secara rutin(Nair \& Peate, 2015). Perkeni dalam hasil konsesusnya tahun 2015 menyebutkan langkah-langkah pengelolaan DM meliputi penerapan pola hidup sehat melalui pengelolaan menu diet sehat DM serta merutinkan aktivitas fisik selain itu juga dibarengi dengan terapi farmakologis DM yaitu berupa pemberian obat anti hiperglikemik oral. Hasil intervensi pengabdian masyarakat pada penderita DM kelompok lansia oleh Ratnawati, dkk., (2018) berupa penyuluhan kesehatan mengenai diabetes mellitus, modifikasi menu diet DM dan mengajarkan senam kaki diabetik menunjukkan adanya peningkatan pengetahuan pada lansia mengenai DM sebanyak 83,56\%. Selain itu, juga didapatkan adanya perubahan informasi dan ketrampilan pengelolaan DM pada kelompok lansia yaitu sebesar 
48,26\%. Salah satu gejala diabetes adalah sering makan, mudah lapar. Kondisi tersebut menunjukkan pentingnya pembuatan makanan yang tepat untuk penderita diabetes mellitus, yaitu makanan selingan yang mengandung kadar gula darah rendah. Bahan makanan yang dapat digunakan dalam pembuatan makanan selingan yang tepat bagi penderita DM yaitu oatmeal.

Hasil riset Khandghawi et al., (2016) dan Mottalib et al., (2016) menyebutkan bahwa oatmeal merupakan makanan yang dianjurkan bagi penderita DM karena oatmeal merupakan jenis polisakarida yang mengandung $\beta$-glucan, sehingga dapat membantu menurunkan kadar gula darah post prandial penderita DM tipe 2 . Adanya kandungan $\beta$-glucan dalam oatmeal yang sangat membantu penderita diabetes mellitus, maka oatmeal dapat diberikan sebagai makanan pagi atau snack sebanyak 1,3 gram per penyajian. Tappy et al., (1996) dalam Mottalib, et al., (2016) menyebutkan bahwa $\beta$-glucan sebanyak 6 gram per hari dapat membantu menurunkan kadar gula darah post prandial hingga $10 \%$. Remya \& Davis (2017) menyebutkan konsumsi oatmeal lebih disarankan bagi penderita DM dibanding mengkonsumsi nasi, hasil riset Remya dan Davis menunjukkan bahwa diet nasi pada penderita DM tidak membantu menurunkan kadar gula darah post prandial pada semua responden, hanya $33 \%$ responden yang mampu mencapai kadar gula darah post prandial $<110 \mathrm{mg} / \mathrm{dl}$, sementara pada diet oatmeal terbukti seluruh responden dapat mencapai kadar gula darah post prandial < $110 \mathrm{mg} / \mathrm{dl}$. Nasi terbukti sebagai salah 1 jenis makanan yang dapat memicu naiknya kadar gula darah baik pada penderita DM maupun bukan penderita diabetes mellitus.

Dari data Dinas Kesehatan Kota Samarinda (2018) diketahui bahwa penderita DM di daerah Samarinda Ilir tercatat paling banyak se-Kota Samarinda. Untuk itulah diperlukan pelatihan mengenai pembuatan snack yang tepat bagi penderita diabetes mellitus. Selain itu, mayoritas ibu- ibu Nasyiatul Aisyiyah tidak bekerja sehingga dengan memiliki ketrampilan dalam membuat biscuit diharapkan dapat menambah penghasilan mereka. Tujuan dari pengabdian masyarakat ini yaitu untuk meningkatkan pengetahuan anggota Nasyiatul Aisyiyah mengenai DM dan untuk meningkatkan ketrampilan anggota Nasyiatul Aisyiyah dalam pembuatan biscuit crackers oatmeal. Manfaat kegiatan ini yaitu membantu meningkatkan pengetahuan anggota Nasyiatul Aisyiyah mengenai DM dan membantu para anggota Nasyiatul Aisyiyah agar memiliki peluang menambah penghasilan dari pembuatan biscuit crackers oatmeal.

\section{Metode Pelaksanaan}

Tempat dan Waktu. Tempat pelaksanaan pelatihan di wilayah Kelurahan Sungai Dama Samarinda Ilir, Kota Samarinda Provinsi Kalimantan Timur, dilaksanakan selama 2 bulan sejak 12 Juli 2018 hingga 12 September 2018.

\section{Khalayak Sasaran.}

Terdapat 16 anggota Nasyiatul Aisyiyah di wilayah Kelurahan Sungai Dama Kota Samarinda, yang merupakan ibu- ibu rumah tangga. Namun dari 16 orang peserta, hanya 2 orang peserta yang gagal dalam evaluasi pembuatan crackers.

\section{Metode Pengabdian}

Pengabdian ini terdiri dari 2 kegiatan yaitu :

1. Penyuluhan tentang penyakit diabetes mellitus, dilakukan pada minggu pertama, dan dilanjutkan dengan evaluasi mengenai pengetahuan peserta mengenai DM pada minggu ke- 2 di rumah salah satu anggota Nasyiatul Aisyiyah.

2. Pelatihan pembuatan biscuit crackers oatmeal serta pelatihan pembuatan kemasan dilakukan pada minggu ke-3 hingga minggu ke- 8. Pendampingan dilakukan setiap 2 minggu dimulai dari setelah pelatihan yaitu pada minggu ke5 dan minggu ke-7. 
Indikator Keberhasilan. $90 \%$ peserta memiliki pengetahuan yang baik mengenai diabetes mellitus. $90 \%$ peserta mengalami peningkatan pengetahuan mengenai diabetes mellitus. $90 \%$ peserta mampu membuat biscuit crackers oatmeal dengan komposisi yang tepat dan rasa yang pas.

Metode Evaluasi. Ada dua metode evaluasi yaitu evaluasi pengetahuan peserta mengenai DM dilakukan sebelum dan setelah diberi penyuluhan dengan menggunakan kuesioner dengan topik pertanyaan terkait DM dan Evaluasi ketrampilan dan kemampuan peserta dalam pembuatan biscuit crackers oatmeal dilakukan pada minggu ke-8.

\section{Hasil dan Pembahasan}

\section{A. Penyuluhan}

Kegiatan penyuluhan kesehatan mengenai DM diikuti oleh 12 kader Nasyiatul Aisyiyah Samarinda Ilir, semua peserta mengikuti kegiatan hingga selesai. Bentuk evaluasi pada kegiatan ini berupa pemberian kuesioner yang berisi 10 pertanyaan. Evaluasi dilakukan sebelum peserta diberi penyuluhan kesehatan dan seminggu setelah diberi penyuluhan, dengan menggunakan kuesioner yang berisi 10 pernyataan berupa pengertian diabetes mellitus, tanda gejala, komplikasi, perawatan dan pemberian diet DM yang benar.

Tabel 1. hasil evaluasi pengetahuan DM

\begin{tabular}{|c|c|c|c|}
\hline \multirow[t]{2}{*}{ No } & \multirow[t]{2}{*}{ Pernyataan } & \multicolumn{2}{|c|}{$\begin{array}{l}\text { Jumlah Responden } \\
\text { Menjawab Benar }\end{array}$} \\
\hline & & Sebelum & Setelah \\
\hline 1 & DM merupakan penyakit menular & 7 & 10 \\
\hline 2 & $\begin{array}{l}\text { DM merupakan penyakit yang ditandai dengan } \\
\text { tingginya kadar gula darah dalam tubuh }\end{array}$ & 7 & 8 \\
\hline 3 & DM bisa sembuh & 5 & 8 \\
\hline 4 & $\begin{array}{l}\text { DM dapat menyebabkan munculnya penyakit } \\
\text { jantung, stroke }\end{array}$ & 3 & 9 \\
\hline 5 & $\begin{array}{l}\text { Pijat dan kerokan merupakan bentuk terapi } \\
\text { diabetes mellitus }\end{array}$ & 7 & 10 \\
\hline 6 & Obat untuk penderita DM berupa insulin & 3 & 8 \\
\hline 7 & $\begin{array}{l}\text { Mata kabur, kesemutan, mudah capek, lemas, } \\
\text { merupakan tanda diabetes mellitus }\end{array}$ & 4 & 9 \\
\hline 8 & $\begin{array}{l}\text { Nasi putih hangat, teh manis, tidak dianjurkan } \\
\text { dikonsumsi bagi penderita diabetes mellitus }\end{array}$ & 5 & 8 \\
\hline 9 & $\begin{array}{l}\text { Olahraga selama } 30 \text { menit perhari baik bagi } \\
\text { penderita diabetes mellitus }\end{array}$ & 5 & 7 \\
\hline 10 & $\begin{array}{l}\text { Oat merupakan contoh nutrisi baik untuk } \\
\text { penderita DM }\end{array}$ & 2 & 8 \\
\hline
\end{tabular}

Sebelum diberikan penyuluhan kesehatan, skor rata- rata peserta mencapai 35,8 , setelah diberi penyuluhan, skor rata- rata peserta mencapai 60. Peningkatan pengetahuan peserta setelah diberi penyuluhan kesehatan mencapai $24,17 \%$. Evaluasi diberikan 1 minggu pasca pemberian materi penyuluhan kesehatan sehingga sebagian besar peserta tidak mengingat materi yang telah disampaikan. Hasil evaluasi yang dilakukan oleh Ratnawati dkk., (2018) mengenai pengetahuan peserta kelompok lansia menunjukkan adanya peningkatan pengetahuan hingga 83,56 \%, hal ini sangat jauh berbeda dengan hasil abdimas ini yang hanya mencapai $24,17 \%$.

Sebelum diberi penyuluhan, sebagian besar peserta tidak mampu menjawab dengan tepat mengenai jenis terapi DM, Komplikasi, tanda gejala, diet sehat DM 
dan pengelolaan DM. Pada evaluasi setelah diberi penyuluhan, sebagian besar peserta tidak mampu menjawab pada item terapi, perawatan, komplikasi dan tanda gejala.

Hasil ini berbeda dengan hasil riset Wardatu dkk., (2019) yang menunjukkan sebagian besar responden memiliki pengetahuan yang baik mengenai diet DM. Hasil riset Bertalina \& Anindyati (2016) menunjukkan bahwa ada hubungan antara pengetahuan mengenai terapi diet DM dengan kadar indeks glikemik makanan konsumsi harian. Dalam hal ini pengetahuan menurut Alfiani dkk., (2017 dalam Wardatu, 2019) dapat dipengaruhi oleh usia, pekerjaan dan pendidikan.

\section{B. Pelatihan}

Pelatihan pembuatan biskuit crackers oatmeal yang semula diikuti oleh 12 peserta tetapi ada 4 peserta tambahan yang ingin mengikuti pelatihan diluar 12 peserta sebelumya, semua peserta mengikuti kegiatan hingga selesai acara.

Evaluasi pembuatan biskuit crackers oatmeal pada 16 peserta, 14 peserta mampu membuat biskuit dengan rasa yang renyah, enak dan tidak gosong, 2 peserta gagal membuat biskuit dengan benar hal ini disebabkan karena proses pemanggangan tidak tepat (suhu panggangan terlalu tinggi $>220^{\circ} \mathrm{C}$ seharusnya $170^{\circ} \mathrm{C}$ dalam waktu 10-15 menit, waktu terlalu pendek dari yang diajarkan), perpaduan komposisi tidak sesuai takaran, biskuit terasa pahit karena agak gosong.

Pelatihan pembuatan kemasan biscuit, dalam pelatihan ini peserta diajarkan cara membuat label dan kemasan yang menarik hingga memungkinkan dapat dijual sebagai produk bernilai tinggi. Skema pelatihan diringkas pada Gambar 1.

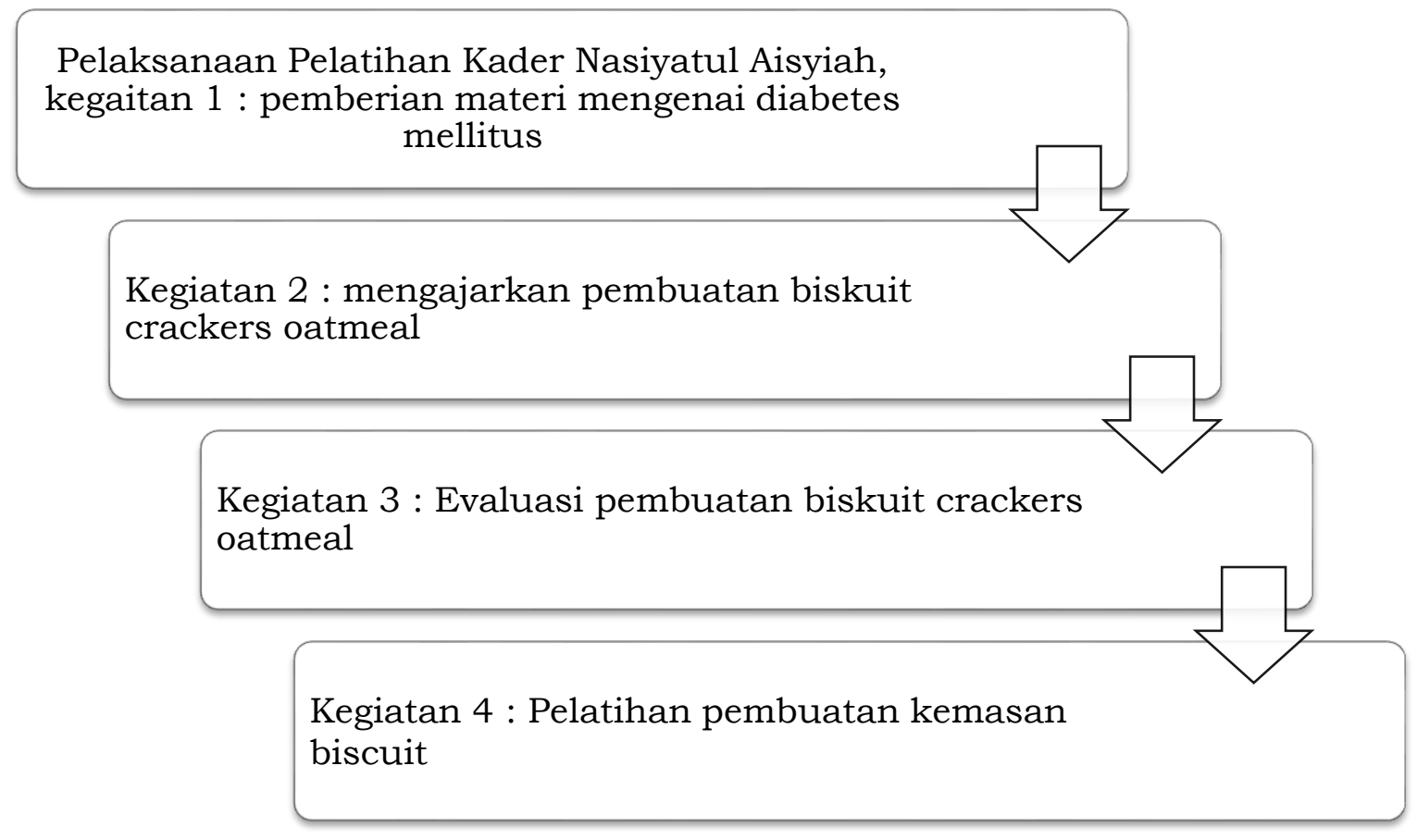

Gambar 1. Skema Pelatihan

\section{Keberhasilan Kegiatan}

Dari 16 anggota Nasyiatul Aisyiyah yang di berikan penyuluhan dan pelatihan pembuatan biskuit Oatmeal untuk penderita diabetes sebagian besar berhasil mengikuti dan menyelesaikan penyuluhan dan pelatihan. Namun dari 16 orang peserta, hanya 2 orang peserta yang gagal dalam evaluasi pembuatan crackers. Sebagian besar peserta pelatihan $(87,5 \%)$ mampu mengetahui DM secara baik dan 
mampu membuat dan mengemas biscuit crackers oatmeal secara tepat dan benar.

\section{Kesimpulan}

Sebagian besar 87,5\% atau 14 kader Nasyiatul Asiyiyah Samarinda Ilir mampu membuat biscuit oatmeal secara tepat, sebagian besar peserta pelatihan memiliki pengetahuan yang baik mengenai DM.

\section{Ucapan Terima Kasih}

Penulis mengucapkan terima kasih yang sebesar- besarnya kepada pihak LPPM UMKT yang telah memberikan hibah internal pengabdian masyarakat kepada penulis dan tim sehingga dapat melakukan pengabdian masyarakat bagi warga Samarinda Ilir, warga Samarinda Ilir yang telah meluangkan waktunya untuk mengikuti pelatihan.

\section{Referensi}

Bertalina., A. (2016) Hubungan Pengetahuan Terapi Diet Dengan Indeks Glikemik Bahan Makanan Yang Dikonsumsi Pasien Diabetes Mellitus. Jurnal Kesehatan, VII(3), November 2016, 377-387.

Dinas Kesehatan Kota Samarinda. Data Diabetes Mellitus tahun 2018.

Kemenkes Republik Indonesia. (2018). Hasil Utama Riskesdas 2018.

Khandgawi, M. A., Morsi, A.N., \& Mohamed, L.H. (2016). Impact Of Oat-Beta

Glucan In Blood Glucose Levels Among Type 2 Diabetic Pateints. World Journal of Pharmaceutical Research. 5(6), 1953-1956.

Mottalib, A., Mohd-Yusof, B-N., Shehabeldin, M., Pober, D.M., Mitri, J., \& Hamdy, O. (2016). Impact of Diabetes-Specific Nutritional Formulas versus Oatmeal on Postprandial Glucose, Insulin, GLP-1 and Postprandial Lipidemia. Nutrients, 8(443), 1-11.

Nair, M., \& Peate, I. (2015). Dasar-Dasar Patofisiologi Terapan. Jakarta. Bumi Medika. ed 2. editor bahasa indonesia Yanita Nur Indah Sari, Restu Damayanti.

Perkeni. (2015). Konsensus Pengelolaan dan pencegahan Diabetes melitus tipe 2 di Indonesia 2015. PB ERKENI. Jakarta.

Pusdatin Kemenkes Republik Indonesia. (2014). Infodatin Situasi dan Analisis Diabetes. Pusdatin Kemenkes RI. Jakarta.

Ratnawati, D., Siregar, T., \& Wahyudi, C.T. (2018). IbM Kelompok Lansia Penderita Diabetes Melitus (DM) di Wilayah Kerja Puskesmas Limo Kota Depok Jawa Barat. Jurnal Panrita Abdi, 2(2), 93-104.

Remya, P.R., \& Davis, A. (2017). Comparison of Glycemic Responses of Various Cereal based Breakfast Items in Diabetic and Non-Diabetic Individual. Indian Journal of Nutrition, 4(1), 1-5.

Wardatu, A., Kurniati, A.M., Rasyid, R.S.P., Husin, S., Liniyanti D., \& Oswari, L.D. (2019). Hubungan Tingkat Pengetahuan tentang Makronutrien dengan Kecukupan dan Keseimbangan Asupan Makronutrien Pasien Diabetes Melitus Tipe 2. Sriwijaya Journal of Medicine, 2 (2), 94-98.

Penulis:

Fatma Zulaikha Prodi S1 Keperawatan, Fakultas Ilmu Kesehatan dan Farmasi, Universitas Muhammadiyah Kalimantan Timur.Samarinda. E-mail: fz658@umkt.ac.id

Enok Sureskiarti, Prodi S1 Keperawatan, Fakultas Ilmu Kesehatan dan Farmasi, Universitas Muhammadiyah Kalimantan Timur.Samarinda, E-mail: es202@umkt.ac.id

Nunung Herlina, Prodi S1 Keperawatan, Fakultas Ilmu Kesehatan dan Farmasi, Universitas Muhammadiyah Kalimantan Timur.Samarinda. E-mail: $\underline{\text { nh183@umkt.ac.id }}$

Bagaimana men-sitasi artikel ini:

Zulaikha, F., Sureskiarti, E., \& Herlina, N. (2020). Pelatihan Cara Pembuatan Makanan Ringan Rendah Gula bagi Penderita Diabetes Mellitus. Jurnal Panrita Abdi, 4 (1), 77 - 82. 